\title{
Influence of Granulocytes on Brain Edema, Intracranial Pressure, and Cerebrospinal Fluid Concentrations of Lactate and Protein in Experimental Meningitis
}

\author{
Martin G. Täuber, Urs Borschberg, \\ and Merle A. Sande
}

\author{
From the Division of Infectious Diseases, Department of \\ Medicine, University Hospital, Zurich, Switzerland; the \\ Medical Service, San Francisco General Hospital, and the \\ University of California, San Francisco, California
}

\begin{abstract}
Brain water content (brain edema), intracranial pressure, and cerebrospinal fluid (CSF) concentrations of lactate and protein increased significantly during $24 \mathrm{~h}$ of experimental meningitis due to Streptococcus pneumoniae, but changes were similar in normal and neutropenic rabbits. In sterile meningitis induced by $N$-formyl-methionyl-leucyl-phenylalanine (fMLP), low and high doses of fMLP were equally effective in inducing CSF pleocytosis, whereas only high doses of fMLP caused brain edema. High doses of fMLP injected intracisternally during pneumococcal meningitis also increased brain water content. The fMLP did not significantly increase intracranial pressure or CSF concentrations of lactate or protein in sterile or pneumococcal meningitis, nor did it cause brain edema in neutropenic animals. Thus, granulocytes may contribute to brain edema during meningitis if adequately stimulated, but intracranial pressure and CSF protein and lactate concentrations appear independent of granulocytes. Stimulation does not appear to occur early in meningitis, when granulocytes were without effect on brain edema.
\end{abstract}

Morbidity and mortality from bacterial meningitis remain high [1-4]. Pneumococcal meningitis has, even in recent years, a death rate of almost $30 \%$ [3, 4]. This figure has not changed in the last 40 years, despite new antibiotics and an improved understanding of the principles of antibiotic therapy [5-7].

The functional and morphological substrates of brain damage induced by bacterial meningitis are only partially understood. Early pathological observations have indicated that brain edema and thrombosis of cerebral vessels may contribute to the loss of neuronal functions [8-10]. In addition, evidence exists that meningitis is often associated with in-

Received for publication 29 June 1987, and in revised form 18 September 1987.

This work was presented in part at the 26th Interscience Conference on Antimicrobial Agents and Chemotherapy, held in New Orleans, Louisiana, on 28 September-1 October 1986.

These studies were supported in part by a fellowship grant to Dr. Täuber, by grant 3.936-0.84 from the Swiss National Foundation for Scientific Research, and by a grant from Ciba-Geigy, Ltd., Basel, Switzerland.

We thank Mike Rusnak, Kenyon Scott, Todd Carpenter, Felicia Stella, and Manuela Deflorin for technical assistance and Dr. Ruedi Lüthy for discussion of the manuscript.

Please address requests for reprints to Dr. Martin G. Täuber, Medizinische Poliklinik, Rämistrasse 100, 8091 Zurich, Switzerland. creased intracranial pressure and that this factor may in turn impair cerebral blood flow and thus limit the supply of oxygen and nutrients to the brain [11-13]. Increased CSF outflow resistance [14], impaired cerebral circulation [15], increased intracranial pressure, and brain edema $[16,17]$ have been documented in animal models. These changes are likely to cause the brain to shift its energy production to anaerobic glycolysis and thus increase the production of lactate [18]. Increased lactate concentrations in CSF can be documented readily during meningitis $[19,20]$.

Some evidence exists that both mortality and the development of neurological sequelae may be related to inflammatory CNS alterations. In animal studies the time of death is associated with maximal inflammation in the subarachnoidal space [21], and one study suggested that neutropenic dogs with pneumococcal meningitis may survive longer than animals with a normal inflammatory reaction in the CSF [22]. Fishman et al. [23], Chan and Fishman [24], and Chan et al. [25] have demonstrated that products of leukocytes, such as polyunsaturated fatty acids and oxygen-free radicals, can induce brain edema, increased lactate production, and energy depletion in cortical brain slices of rats. However, the role of leukocytes in the mediation of brain edema during bacterial meningitis has not been examined. Whether other changes observed during 
meningitis, for example, increased intracranial pressure, are mediated by leukocytes is also not known.

Demonstrating harmful effects of leukocytes in the subarachnoidal space during meningitis could have therapeutic consequences. We therefore evaluated the influence of granulocytes on various pathophysiological parameters in an animal model of meningitis. Brain edema, increased intracranial pressure, and changes in CSF concentrations of lactate and protein were examined during bacterial meningitis in normal and in neutropenic rabbits. In addition, these studies were expanded using a model of sterile meningitis in which granulocytic pleocytosis in CSF was induced using a chemotactically active peptide.

\section{Materials and Methods}

Infecting organism. A type 3 encapsulated Streptococcus pneumoniae originally isolated from a clinical specimen [26] was grown on blood agar plates, resuspended in $0.9 \% \mathrm{NaCl}$, and stored at $-70 \mathrm{C}$. For infecting animals, the thawed inoculum was either diluted directly to the desired concentration in $0.9 \% \mathrm{NaCl}$ (first set of experiments) or was grown in Todd-Hewitt broth for $6 \mathrm{~h}$, washed, and suspended in $0.9 \% \mathrm{NaCl}$ (third set of experiments). The actual titer of the inoculum was determined by quantitative cultures on blood agar plates.

Model of experimental pneumococcal meningitis. The model of experimental meningitis in rabbits originally described by Dacey and Sande [27] was used. New Zealand white rabbits weighing 2-3 $\mathrm{kg}$ were anesthetized iv with $30 \mathrm{mg}$ of pentobarbi$\mathrm{tal} / \mathrm{kg}$ (Carter-Glogau Laboratory, Glendale, Ariz) for all experimental procedures. A helmet formed with dental acrylic was attached to the skull by four screws with the animal under general anesthesia, which allowed placement of the animals in stereotactic frames constructed to puncture the cisterna magna (provided by Dr. O. Zak, Ciba-Geigy, Basel, Switzerland). Three days after attachment of the helmet, the animals were again anesthetized with pentobarbital and placed in the stereotactic frames. The cisterna magna was punctured with a spinal needle (3.5 inches; 25 gauge; Becton, Dickinson and Co., Rutherford, NJ). After the pressure was recorded (see below), $0.5 \mathrm{~mL}$ of CSF was withdrawn, and 5-7 $\times$ $10^{5} \mathrm{cfu}$ of $S$. pneumoniae suspended in $0.5 \mathrm{~mL}$ of $0.9 \% \mathrm{NaCl}$ was injected into the cisterna magna. Twenty-four hours later anesthesia was reinduced, the animals were placed in the stereotactic frames, and the cisterna was punctured for collection of CSF and measurement of the other experimental parameters. At the time of infection and after $24 \mathrm{~h}$, blood was collected by cardiac puncture with a 25 gauge, 5/8-inch needle so that the white blood cell (WBC) and differential counts could be determined.

Neutropenic rabbits. Neutropenia was induced in some experimental groups of rabbits by injection of mechlorethamine $\mathrm{HCl}$ (nitrogen mustard; Merck Sharp \& Dohme, West Point, Pa), $1.85 \mathrm{mg} / \mathrm{kg}$ iv, three days before infection or intracisternal injection of a chemotactic stimulus. Simultaneously with the injection of nitrogen mustard, the animals received $1.2 \times 10^{6} \mathrm{U}$ of procaine penicillin im so that Pasteurella multocida pneumonia during neutropenia was prevented. At the time of induction of meningitis, three days later, peripheral WBC and differential counts were determined. Neutropenic animals were not visibly sick at this point.

Chemotactic peptide-induced sterile meningitis. Sterile meningitis was induced in normal and neutropenic rabbits by intracisternal injection of a solution of $N$-formyl-t-methionyl-L-leucyl-L-phenylalanine (fMLP; Sigma, St. Louis). Two doses of fMLP were examined: a low dose with $10^{-5} M$ fMLP and a high dose with $10^{-3} M$ fMLP. fMLP was diluted in $0.1 \%$ (vol/vol) dimethyl sulfoxide and PBS and was injected into the cisterna magna in a volume of $0.5 \mathrm{~mL}$ after removal of an equal volume of CSF. Animals received three injections of fMLP $5 \mathrm{~h}$ apart and underwent final examination $24 \mathrm{~h}$ after the experiment began. One injection of the fMLP carrier alone did not induce CSF pleocytosis of $>50$ $\mathrm{WBCs} / \mathrm{mm}^{3}$ in any of the five control animals. The carrier also did not affect the intracranial pressure of rabbits with pneumococcal meningitis. Before injections of fMLP and at the end of the experiment, WBC counts and all other experimental parameters were determined in CSF.

Stimulation of granulocytes in CSF of rabbits with pneumococcal meningitis. In some animals infected with $S$. pneumoniae, the cisterna magna was punctured $20 \mathrm{~h}$ after infection, $0.5 \mathrm{~mL}$ of CSF was removed and examined, and $0.5 \mathrm{~mL}$ of $10^{-3} \mathrm{M} \mathrm{fMLP}$, prepared as described above, was injected intracisternally so that the WBCs present in the subarachnoidal space were stimulated. Control animals simultaneously received the same amount of $0.9 \% \mathrm{NaCl}$. The animals underwent final examination $4 \mathrm{~h}$ later as described above. 
Experimental parameters. CSF from the cisterna magna was collected through the spinal needle. Bacterial titers in CSF were determined quantitatively by culturing 10-fold dilutions of CSF on blood agar plates incubated overnight at $35 \mathrm{C}$ in room air with $5 \% \mathrm{CO}_{2}$. WBC counts in CSF and blood were determined in a Neubaur hemacytometer. Differential WBC counts were done using smears stained with Giemsa stain. For determination of lactate and protein concentrations, CSF was centrifuged for $30 \mathrm{~s}$ within minutes after collection. The supernatant was frozen immediately at $-70 \mathrm{C}$. Samples were then analyzed using commercially available methods and a centrifugal analyzer in a routine chemical laboratory. Lactate content was determined using an enzymatic method that detects the generation of pyruvate in the presence of lactate dehydrogenase (Monotest Lakatat ${ }^{\circledR}$; Boehringer, Mannheim, Federal Republic of Germany). Protein content was determined using a colorimetric method (total protein test; Bio-Rad, Glattbrugg, Switzerland).

Intracisternal pressure was determined through the spinal needle placed in the cisterna magna while the anesthetized rabbits were secured in a sitting position [16]. Pressure was recorded on a multichannel polygraph (Grass Instrument Co., Quincy, Mass; or Gilson Medical Electronics, Middleton, Wis) by connecting the needle to a water-filled mechanical pressure transducer (Gould Statham model P23ID; Gould, Oxnard, Calif). Each animal served as its own control, and results were expressed as change in pressure from the baseline (preinfection) value. Determination of pressure was considered accurate when mean pressure was stable during a 10 -s period and when respiration-induced changes could be identified on the recording. This method revealed an intraassay reproducibility of $<1 \mathrm{~mm} \mathrm{Hg}$.

At the end of the experiment, $24 \mathrm{~h}$ after infection or induction of sterile meningitis, animals were killed by an iv overdose of pentobarbital. The skull was opened beneath the helmet, and the brain was immediately removed and dissected on filter paper. One hemisphere was weighed and then dried to a stable dry weight in a vacuum oven at $105 \mathrm{C}$ [16]; the other hemisphere was dissected into gray and subcortical white matter, and these fractions were also weighed and dried. Brain water content was then calculated and expressed as grams of water per $100 \mathrm{~g}$ of dry weight. Minimal technical modifications were introduced in an attempt to increase the reproducibility of the brain water determination. These modifica- tions influenced the normal values of brain water content in uninfected controls. Thus in each phase of the experiments, separate groups of uninfected animals were included as controls. These animals were examined simultaneously with the corresponding experimental animals by using identical techniques.

Statistics. Results are expressed as mean \pm SD values unless stated otherwise. Groups were compared by the Student's $t$ test; paired values were examined by the paired $t$ test.

\section{Results}

Normal vs. neutropenic rabbits. In a first set of experiments the role of granulocytes in the development of brain edema, increased intracranial pressure, and increased CSF concentrations of lactate and protein during meningitis was evaluated by comparing the effect of pneumococcal meningitis in normal and neutropenic rabbits. Fifty rabbits were divided into four groups: normal uninfected, normal infected, neutropenic uninfected, and neutropenic infected. On the day of the experiments, neutropenic rabbits had peripheral WBC counts of $550 \pm 350 / \mathrm{mm}^{3}$ compared with $6500 \pm 2020 \mathrm{WBCs} / \mathrm{mm}^{3}$ in normal rabbits $(P<.001)$. In neutropenic rabbits, granulocytes consistently accounted for $<10 \%$ of the peripheral WBCs, compared with $35.2 \% \pm 14.4 \%$ in normal rabbits $(P<.001)$. All other experimental parameters were not significantly different in neutropenic rabbits compared with healthy controls.

Table 1. WBC counts and bacterial titers in CSF of rabbits with experimental meningitis.

\begin{tabular}{lcc}
\hline Experimental group (n) & WBC count & Bacterial titer \\
\hline Infected & & \\
$\quad$ Normal (14) & $2200(350-7050)^{*}$ & $5.7 \pm 0.9$ \\
$\quad$ Neutropenic (12) & $138(13-500)^{\dagger}$ & $5.9 \pm 1.1$ \\
fMLP & $1400(340-4500)^{*}$ & Sterile \\
$\quad$ Low-dose (5) & $700(400-1000)^{*}$ & Sterile \\
$\quad$ High-dose (5) & & \\
Normal infected, at 20 h & & \\
$\quad$ after infection (29) & $1900(255-8000)^{*}$ & $6.0 \pm 1.3$ \\
Infected (24 h) & & \\
fMLP-stimulated (15) & $3500(595-9200)^{*}$ & $5.6 \pm 1.0$ \\
$\quad$ Saline-injected (14) & $3430(720-9150)^{*}$ & $5.9 \pm 1.5$ \\
\hline
\end{tabular}

NOTE. The WBC count (no. of cells $/ \mathrm{mm}^{3}$ ) is given as median value (range), and bacterial titer $\left(\log _{10}\right.$ no. of $\left.\mathrm{cfu} / \mathrm{mL}\right)$ is given as mean $\pm \mathrm{SD}$.

* More than $90 \%$ of the WBCs were granulocytes.

$\dagger$ All WBCs were mononuclear cells. 
Pneumococcal meningitis induced clinical disease (lethargy and fever) and progressive changes in all experimental parameters. Bacterial titers in CSF after $24 \mathrm{~h}$ of disease were identical in normal and neutropenic rabbits (table 1). WBC counts in CSF were, however, markedly different (table 1 ). In normal rabbits the median CSF WBC count was $2200 / \mathrm{mm}^{3}$, and $>90 \%$ of these cells were granulocytes. In contrast, neutropenic animals had a median of only 138 $\mathrm{WBCs} / \mathrm{mm}^{3}$ in CSF $24 \mathrm{~h}$ after infection, and all these cells were mononuclear cells $(P<.001)$.

Brain water content increased as a result of the infection, but the increase was identical in normal and neutropenic rabbits (figure 1). The water content of hemispheres increased from $392 \pm 8 \mathrm{~g}$ of water $/ 100 \mathrm{~g}$ of dry weight in uninfected normal rabbits and $394 \pm 9 \mathrm{~g} / 100 \mathrm{~g}$ in uninfected neutropenic rabbits to $403 \pm 10$ and $403 \pm 12 \mathrm{~g} / 100 \mathrm{~g}$, respectively $(P<.01$ for normal and neutropenic rabbits combined). The corresponding values for white matter water content were $240 \pm 12 \mathrm{~g} / 100 \mathrm{~g}$ in normal and $242 \pm 19 \mathrm{~g} / 100 \mathrm{~g}$ in neutropenic rabbits to $252 \pm$ 12 and $251 \pm 22 \mathrm{~g} / 100 \mathrm{~g}$, respectively $(P<.05$ for normal and neutropenic rabbits combined). There was also a slight but not statistically significant increase in gray matter water content during infection in both the normal and neutropenic animals.

Intracisternal pressure increased significantly $(P$ $<$.01) during the $24-\mathrm{h}$ infection in normal rabbits and slightly less in neutropenic rabbits (figure $2 \mathrm{~A}$; $4.6 \pm 1.8$ vs. $3.4 \pm 1.8 \mathrm{~mm} \mathrm{Hg}$; difference not sig-

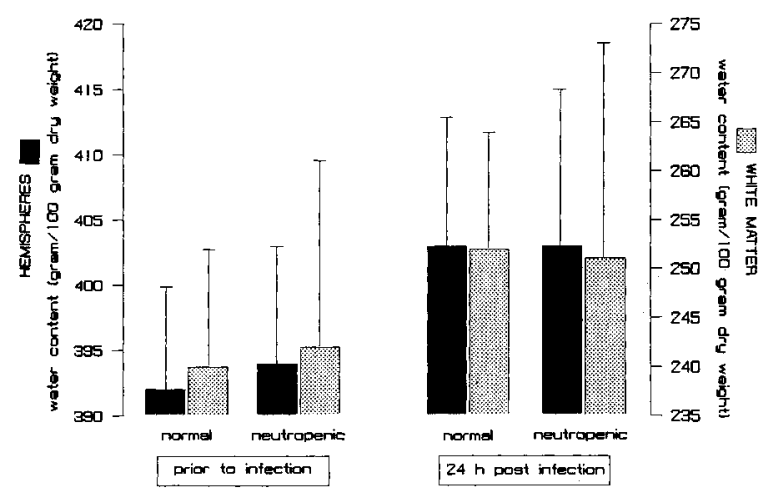

Figure 1. Brain water content in normal and neutropenic rabbits. Animals were examined before and $24 \mathrm{~h}$ after induction of pneumococcal meningitis. Darker columns represent brain water content of hemispheres; lighter columns represent brain water content of subcortical white matter. Data are mean \pm SD (bars) values. The difference between uninfected and infected animals was significant $(P<.05)$.
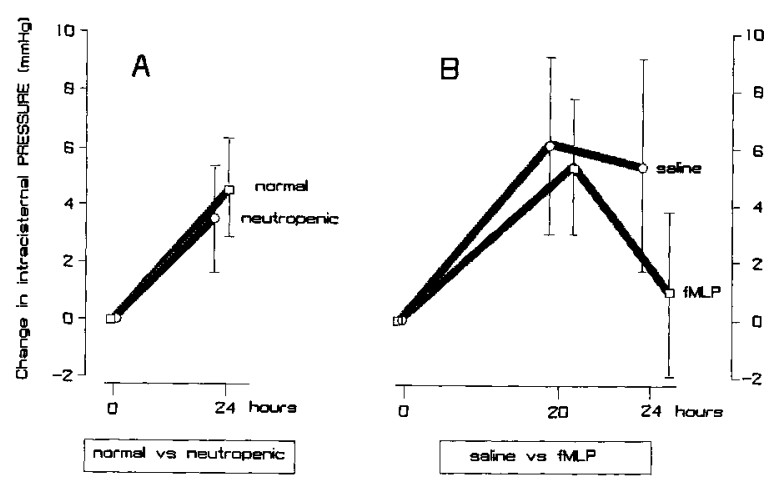

Figure 2. Changes in intracisternal pressure $(\mathrm{mm} \mathbf{H g})$ in animals during pneumococcal meningitis. Data are mean $\pm \mathrm{SD}$ (bars) values. $A$ : Neutropenic animals had an increase in intracisternal pressure during infection, similar to that in the infected controls. $B$ : In animals with pneumococcal meningitis injected with high-dose fMLP $20 \mathrm{~h}$ after induction of infection, pressure decreased significantly $(P<.01)$ compared with control animals, which received saline at $20 \mathrm{~h}$.

nificant). CSF concentrations of lactate and protein increased markedly during meningitis, but there was no significant difference in changes between normal and neutropenic rabbits: for lactate, $1.3 \pm 0.3$ $\mathrm{mmol} / \mathrm{L}$ in uninfected rabbits, $7.14 \pm 3.7 \mathrm{mmol} / \mathrm{L}$ in normal infected animals $(P<.001)$, and $5.25 \pm$ $2.9 \mathrm{mmol} / \mathrm{L}$ in neutropenic infected rabbits (difference not significant); and for protein, $0.5 \pm 0.2 \mathrm{~g} / \mathrm{L}$ in uninfected controls, $2.0 \pm 1.5 \mathrm{~g} / \mathrm{L}$ in normal infected animals $(P<.01)$, and $2.8 \pm 1.4 \mathrm{~g} / \mathrm{L}$ in neutropenic infected animals (difference not significant).

Chemotactic peptide-induced sterile meningitis. A second approach was designed for evaluating the role of granulocytes in the development of pathophysiological changes during meningitis. Sterile meningitis was induced by repeated (three times) intracisternal injection of fMLP into experimental groups of five or six rabbits. The chemotactic and neutrophil-stimulating properties of this oligopeptide have been well characterized in vitro [28-30]. Two doses of fMLP were examined: a low dose with $10^{-5} M$ fMLP per injection and a high dose with $10^{-3}$ $M$ fMLP. If an $\sim 100$-fold dilution in CSF and tissue of animals is assumed, these doses were chosen so that in vivo concentrations in the range of those capable of inducing oxygen free radical generation and degranulation of granulocytes in vitro $[29,30]$ were achieved.

Injections with the lower dose of IMLP were as effective in inducing CSF pleocytosis as were injec- 


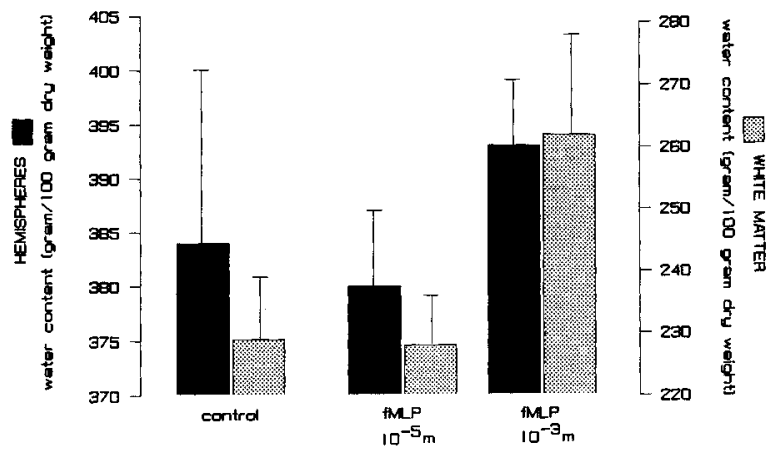

Figure 3. Brain water content in control animals and in rabbits receiving intracisternal injections of low or high doses of fMLP. Darker columns indicate water content of hemispheres; lighter columns indicate water content of subcortical white matter. Data are mean \pm SD (bars) values. The differences between high-dose and low-dose fMLP were significant $(P<.02)$.

tions of the higher dose (table 1). In all animals $>\mathbf{9 0 \%}$ of the cells in the CSF were granulocytes. The pleocytosis induced by low-dose fMLP was not associated with significant changes in any of the experimental parameters (figures 3 and 4). Brain water content of the hemispheres was $380 \pm 7 \mathrm{~g} / 100 \mathrm{~g}$ of dry weight compared with $384 \pm 16 \mathrm{~g} / 100 \mathrm{~g}$ in controls; white matter water content was $228 \pm 8$ $\mathrm{g} / 100 \mathrm{~g}$ compared with $229 \pm 10 \mathrm{~g} / 100 \mathrm{~g}$ in controls (figure 3). CSF pressure did not change significantly during the 24 -h course of sterile meningitis $(0.1 \pm$ $2.7 \mathrm{~mm} \mathrm{Hg}$ ). Similarly, CSF concentrations of lactate $(1.6 \pm 0.2 \mathrm{mmol} / \mathrm{L})$ and protein $(0.4 \pm 0.14 \mathrm{~g} / \mathrm{L})$ were not different from control values (figure 4).

In contrast to the animals receiving low-dose fMLP, the CSF pleocytosis induced by high-dose fMLP had a significant effect on brain water content (figure 3): hemispheres, $393 \pm 6 \mathrm{~g} / 100 \mathrm{~g}$ of dry weight $(P<.02$ vs. low-dose fMLP; difference not significant vs. controls); and white matter, $262 \pm$ $16 \mathrm{~g} / 100 \mathrm{~g}(P<.01)$. This induction of brain edema was associated with an increase in CSF concentrations of protein and lactate $(2.84 \pm 3.60 \mathrm{~g} / \mathrm{L}$ and $2.15 \pm 1.12 \mathrm{mmol} / \mathrm{L}$, respectively; figure 4$)$. However, because not all animals in this group showed chemical alterations of CSF (the SD was large), these differences did not reach statistical significance. CSF pressure did not change significantly during the course of sterile meningitis induced by high-dose fMLP $(0.8 \pm 1.6 \mathrm{~mm} \mathrm{Hg})$.

The possibility that the observed development of brain edema was induced by fMLP itself was ex-

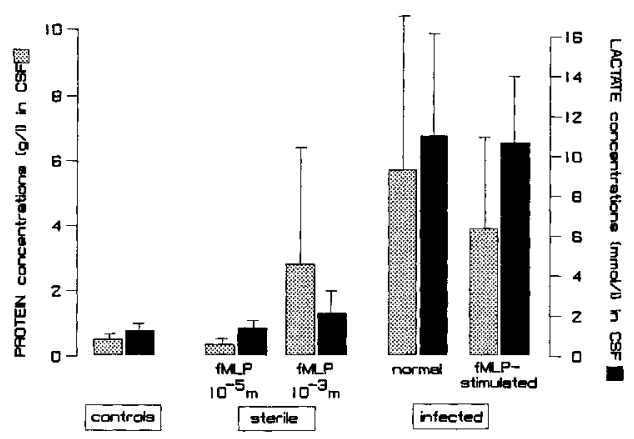

Figure 4. Protein (lighter columns) and lactate (darker columns) concentrations in CSF of rabbits with sterile and pneumococcal ("infected") meningitis. Data are mean \pm $\mathrm{SD}$ (bars) values. Sterile meningitis was induced with three doses of fMLP. Infected animals were compared after intracisternal injection of saline or fMLP $20 \mathrm{~h}$ after infection, $4 \mathrm{~h}$ before they were killed. Infection induced a significant increase in lactate and protein concentrations $(P$ $<.01$ ); all other differences were not significant.

cluded by injection of high-dose fMLP into four neutropenic animals. Brain water content in these animals was not significantly different from that in control animals: hemispheres, $370 \pm 5$ vs. $375 \pm$ $8 \mathrm{~g} / 100 \mathrm{~g}$ of dry weight in controls; and white matter, $222 \pm 14$ vs. $220 \pm 11 \mathrm{~g} / 100 \mathrm{~g}$. Thus these results show that only the CSF pleocytosis (predominantly granulocytes) induced with high-dose fMLP was associated with development of brain edema and a moderate increase in CSF concentrations of lactate and protein.

Stimulation of granulocytes with $f M L P$ during pneumococcal meningitis. Results reported so far are compatible with the hypothesis that activated (high-dose fMLP), in contrast to inactive (low-dose fMLP), granulocytes can contribute to development of brain edema. The lack of a measurable effect of granulocytes on brain edema during the first $24 \mathrm{~h}$ of meningitis (first set of experiments) can be explained by the absence of a sufficient stimulation of granulocytes in the CSF during infection. This proposal is supported by the inability of granulocytes to reduce bacterial titers in CSF [31].

To test this hypothesis we examined the effect of stimulating granulocytes during pneumococcal meningitis. A group of 15 animals with pneumococcal meningitis was injected with high-dose fMLP intracisternally $4 \mathrm{~h}$ before they were killed $(20 \mathrm{~h}$ after infection) in an attempt to stimulate the granulocytes then present in CSF. These animals were compared with 14 animals with pneumococcal meningitis 
receiving $0.9 \% \mathrm{NaCl}$. In both groups, CSF WBCs increased to similar final counts between 20 and $24 \mathrm{~h}$ (table 1). Bacterial titers were also similar in the two groups (table 1).

Intracisternal injection of fMLP was associated with higher brain water content compared with values in infected controls (figure 5): hemispheres, $391 \pm 12$ vs. $381 \pm 10 \mathrm{~g} / 100 \mathrm{~g}$ of dry weight $(P<$ $.03)$; and white matter, $244 \pm 18 \mathrm{vs.} 234 \pm 13 \mathrm{~g} / 100 \mathrm{~g}$ $(P<.1)$. Gray matter water content also increased slightly. As in the previous experiments, infected animals had higher brain water content than did uninfected controls (figure 5).

In parallel with the fMLP-induced increase in brain water, intracisternal pressure was reduced (figure 2B). Twenty hours after infection, when fMLP was injected, intracisternal pressure had increased by 5.4 $\pm 2.3 \mathrm{~mm} \mathrm{Hg}(P<.01)$. Four hours later the pressure had dropped to $0.8 \pm 2.9 \mathrm{~mm} \mathrm{Hg}(P<.01)$, despite the concomitant increase in brain edema. In animals receiving saline intracisternally, the pressure remained stable between 20 and $24 \mathrm{~h}$ (final pressure, $4.7 \pm 3.7 \mathrm{~mm} \mathrm{Hg} ; P<.005$ compared with final pressure in fMLP-treated animals). CSF concentrations of lactate and protein were not significantly affected by intracisternal injection of fMLP and the associated increase in brain edema (figure 4): lactate, $10.7 \pm 3.3$ vs. $11.0 \pm 5.1 \mathrm{mmol} / \mathrm{L}$; and protein, 3.9 \pm 2.8 vs. $5.8 \pm 5.7 \mathrm{~g} / \mathrm{L}$.

\section{Discussion}

That various elements of the body's inflammatory response can be destructive for the host's own tissue has recently become clear. The most important cells involved in such inflammation-associated tissue damage are the neutrophils. Granulocytes have been implicated as playing a key role in the development of adult respiratory distress syndrome [32, 33], even though recent data suggest that this syndrome can also develop in neutropenic individuals [34]. In other situations granulocytic enzymes may develop their harmful activity in conjunction with microbial enzymes, a mechanism that has been documented in the bronchial system of children with cystic fibrosis colonized with Pseudomonas aeruginosa [35]. In arthritis the toxic products of granulocytes that accumulate in the inflamed joint also appear to contribute to development of chronic tissue damage [36, 37].

Some indirect evidence exists that granulocytes

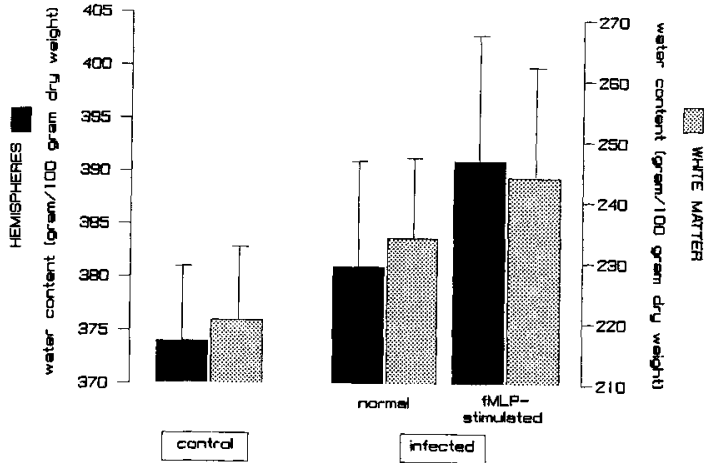

Figure 5. Brain water content in normal uninfected rabbits and in rabbits with pneumococcal meningitis receiving intracisternal saline or fMLP. Saline or high-dose fMLP was injected intracisternally $20 \mathrm{~h}$ after infection, $4 \mathrm{~h}$ before the animals were killed. Darker columns represent hemispheres; lighter columns represent subcortical white matter. Data are mean \pm SD (bars) values. Injection of $\mathrm{fMLP}$ was associated with a significant $(P<.05)$ increase in brain edema.

could also contribute to brain damage during meningitis. Petersdorf and Luttrell [22] found that neutropenic dogs with experimentally induced pneumococcal meningitis survived the infection an average of $62 \mathrm{~h}$ compared with $46 \mathrm{~h}$ for normal dogs with an unimpaired inflammatory response in CSF. The statistical significance of this difference has not been determined. McAllister et al. [21] observed an association between the maximal inflammation in CSF and the time of death in rabbits with experimental pneumococcal meningitis. Extensive work by Fishman et al. [23], Chan and Fishman [24], and Chan et al. [25] has implicated granulocytes as an important factor in development of brain edema. Both arachidonic acid and other free polyunsaturated fatty acids [38-40], which represent major constituents of the granulocytic cell wall and are found in high concentrations in pus, as well as oxygen-derived free radicals $[25,41]$ appear to be involved in the generation of brain edema in vitro and in vivo.

Despite these data the role of granulocytes in the pathogenesis and pathophysiology of bacterial meningitis has not been well defined. In one study Ernst et al. [31] showed that granulocytes in CSF of rabbits with pneumococcal meningitis were ineffective in reducing bacterial growth. This observation has been confirmed in the present study. In their study, changes in CSF concentrations of lactate, protein, and glucose were also examined. There was no obvious difference between normal and neutropenic 
animals, but this conclusion was based on only three neutropenic rabbits examined [31]. A more recent study in rats indicated that leukocytes were not essential for development of increased blood-brain barrier permeability during experimental Haemophilus influenzae meningitis [42].

Here we measured pathophysiological changes that have previously been characterized in this model $[16,43]$. Brain edema was examined because of its association with brain injury due to various causes [44]. In experimental meningitis the development of brain edema, albeit not massive, has been documented $[16,43,45]$, and clinical evidence exists of severe brain edema in fatal cases of meningitis $[8,46]$. According to Fishman et al. [23] and Fishman [44], brain edema during meningitis ("granulocytic edema") comprises all three types of brain edema, i.e., vasogenic edema, cytotoxic edema, and interstitial edema. As shown in this and previous studies, brain edema in experimental meningitis in rabbits develops primarily in the white matter, a localization that is typical for vasogenic edema [43]. Vasogenic edema is the expression of increased permeability of the blood-brain barrier typical for bacterial meningitis [42, 47]. Determination of CSF protein concentrations, which reflect this leakage into the interstitial space, have been included here.

Intracranial pressure was also monitored. Few studies have examined intracranial pressure during meningitis despite the general consensus that pressure increases during the disease $[11-13,17,45]$. Massively increased intracranial pressure may impair cerebral blood flow [48]. Increased brain volume due to swelling is thought to be one mechanism contributing to increased intracranial pressure, but our own experimental data indicate that this mechanism cannot be the only one, because infected animals treated with methylprednisolone had increased pressure despite the absence of brain edema [16].

CSF lactate concentrations were included as an experimental parameter to serve as an indicator of impaired glucose metabolism of the brain [18]. Glucose is the major source of energy of the CNS, and any alteration of this metabolism has potentially serious functional consequences $[49,50]$. Elevated lactate concentrations in CSF, which appear to be only minimally influenced by direct lactate production of bacteria or leukocytes in CSF, have been associated with increased mortality from meningitis in humans [51] and in experimental pneumococcal meningitis [52].

The results of this study indicate that granulocytes are of minor relevance for the pathophysiological alterations examined. All parameters changed significantly when animals were infected, but the virtually complete absence of granulocytes in neutropenic rabbits did not have any significant effect on the magnitude of these changes. Obviously, factors other than granulocytes must be involved. Preliminary studies indicate that bacterial products may be important. Endotoxin released during treatment of Escherichia coli meningitis with a new cephalosporin was responsible for development of brain edema in one study [43]. Products of pneumococcal cell walls induce inflammation, increased intracranial pressure, and brain edema in the same animal model [53-55].

It was only when granulocytes in CSF were stimulated by high doses of fMLP that any effect attributable to granulocytes could be documented, i.e., increased brain edema. Moreover, the increase in brain edema was moderate and was not reflected by increased lactate production. Increased lactate concentrations in CSF would be expected if the additional edema was detrimental to the brain's glucose metabolism. Whether stimulation of granulocytes occurs during meningitis is unknown. The comparison between neutropenic and normal animals indicates that at least during the first $24 \mathrm{~h}$ of the disease there is no substantial stimulation, despite the pronounced inflammatory changes in CSF. The apparent lack of stimulation can be explained by the inefficient phagocytosis by granulocytes [31], which is reflected by the uniformly fatal course of the untreated disease [5]. The increase of brain edema after fMLP stimulation was associated with a decrease in intracisternal pressure. A similar reduction of intracranial pressure was observed in very sick animals with meningitis induced by high doses of pneumococcal cell walls [53]. These observations emphasize that increased brain volume is not necessarily the basis for the increased intracranial pressure.

In summary, these studies show that granulocytes are not important in the development of brain edema, increased intracranial pressure, or changes in CSF concentrations of lactate or protein during the first $24 \mathrm{~h}$ of experimental meningitis due to $S$. pneumoniae. This conclusion modifies the concept of Fishman et al. [23] and Fishman [44] and indicates that brain edema during meningitis may not be "granulocytic" edema. The mere presence of granulocytes in CSF appears to be insufficient to contribute to brain edema or other pathophysiological alterations dur- 
ing bacterial meningitis. Rather, stimulation of the granulocytes is necessary. Further studies must clarify whether such stimulation plays a role in advanced stages of meningitis and whether the release of active products from the infecting bacteria after institution of therapy can stimulate granulocytes in the CSF $[43,56]$.

\section{References}

1. Centers for Disease Control. Bacterial meningitis and meningococcemia-United States, 1978. MMWR 1979;28: 277-9

2. Feigin RD, Dodge PR. Bacterial meningitis: newer concepts of pathophysiology and neurologic sequelae. Pediatr Clin North Am 1976;23:541-56

3. Hodges GR, Perkins RL. Acute bacterial meningitis: an analysis of factors influencing prognosis. Am J Med Sci 1975; 270:427-40

4. Schlech WF III, Ward JI, Band JD, Hightower A, Fraser DW, Broome CV. Bacterial meningitis in the United States, 1978 through 1981. The National Bacterial Meningitis Surveillance Study. JAMA 1985;253:1749-54

5. Täuber MG, Sande MA. The impact of penicillin on the treatment of meningitis. JAMA 1984;251:1877-80

6. Täuber MG, Sande MA. Principles in the treatment of bacterial meningitis. Am J Med 1984;76(5A):224-30

7. Sande MA. Antibiotic therapy of bacterial meningitis: lessons we've learned [editorial]. Am J Med 1981;71:507-10

8. Dodge PR, Swartz MN. Bacterial meningitis - a review of selected aspects. II. Special neurologic problems, postmeningitic complications and clinicopathological correlations. N Engl J Med 1965;272:954-60.

9. Adams RD, Kubik CS, Bonner FJ. The clinical and pathological aspects of influenzal meningitis. Archives of Pediatrics 1948;65:354-76, 408-41

10. Cairns $H$, Russell DS. Cerebral arteritis and phlebitis in pneumococcal meningitis. Journal of Pathology and Bacteriology 1946;58:649-65

11. Goiten KJ, Tamir I. Cerebral perfusion pressure in central nervous system infections of infancy and childhood. J Pediatr $1983 ; 103: 40-3$

12. McMenamin JB, Volpe JJ. Bacterial meningitis in infancy: effects on intracranial pressure and cerebral blood flow velocity. Neurology 1984;34:500-4

13. Paulson OB, Brodersen P, Hansen EL, Kristensen HS. Regional cerebral blood flow, cerebral metabolic rate of oxygen, and cerebrospinal fluid acid-base variables in patients with acute meningitis and with acute encephalitis. Acta Med Scand 1974;196:191-8

14. Scheld WM, Dacey RG, Winn HR, Welsh JE, Jane JA, Sande MA. Cerebrospinal fluid outflow resistance in rabbits with experimental meningitis. Alterations with penicillin and methylprednisolone. J Clin Invest 1980;66:243-53

15. Smith AL, Roberts MC, Haas JE, Stull TL, Mendelman PM. Mechanisms of Haemophilus influenzae type b meningitis. In: Sande MA, Smith AL, Root RK, eds. Bacterial meningitis. New York: Churchill Livingstone, 1985:11-21

16. Täuber MG, Khayam-Bashi H, Sande MA. Effects of am- picillin and corticosteroids on brain water content, cerebrospinal fluid pressure, and cerebrospinal fluid lactate levels in experimental pneumococcal meningitis. $\mathbf{J}$ Infect Dis 1985;151:528-34

17. Goiten KJ, Shapiro M, Ramaz M. Intracranial pressure in experimental Streptococcus pneumoniae meningitis in rabbits. In: Miller JD, Teasdale GM, Rowan JO, Galbraith SL, Mendelow AD, eds. Intracranial pressure VI. Berlin: Springer-Verlag, 1986:507-11

18. Brook I. The importance of lactic acid levels in body fluids in the detection of bacterial infections. Rev Infect Dis $1981 ; 3: 470-8$

19. Gould IM, Irwin WJ, Wadhwani RR. The use of cerebrospinal fluid lactate determination in the diagnosis of meningitis. Scand J Infect Dis 1980;12:185-8

20. Brook I, Bricknell KS, Overturf GD, Finegold SM. Measurement of lactic acid in cerebrospinal fluid of patients with infections of the central nervous system. J Infect Dis 1978; 137:384-90

21. McAllister CK, O'Donoghue JM, Beaty HN. Experimental pneumococcal meningitis. II. Characterization and quantitation of the inflammatory process. J Infect Dis 1975;132: 355-60

22. Petersdorf RG, Luttrell CN. Studies on the pathogenesis of meningitis. I. Intrathecal infection. J Clin Invest 1962;41: 311-9

23. Fishman RA, Sligar K, Hake RB. Effects of leukocytes on brain metabolism in granulocytic brain edema. Ann Neurol 1977;2:89-94

24. Chan PH, Fishman RA. Brain edema: induction in cortical slices by polyunsaturated fatty acids. Science 1978;201: 358-60

25. Chan PH, Schmidley JW, Fishman RA, Longar SM. Brain injury, edema, and vascular permeability changes induced by oxygen-derived free radicals. Neurology 1984;34:315-20

26. Täuber MG, Doroshow CA, Hackbarth CJ, Rusnak MG, Drake TA, Sande MA. Antibacterial activity of $\beta$-lactam antibiotics in experimental meningitis due to Streptococcus pneumoniae. J Infect Dis 1984;149:568-74

27. Dacey RG, Sande MA. Effect of probenecid on cerebrospinal fluid concentrations of penicillin and cephalosporin derivatives. Antimicrob Agents Chemother 1974;6:437-41

28. Schiffmann E, Corcoran BA, Wahl SM. N-Formylmethionyl peptides as chemoattractants for leucocytes. Proc Natl Acad Sci USA 1975;72:1059-62

29. McPhail LC, Snyderman R. Activation of the respiratory burst enzyme in human polymorphonuclear leukocytes by chemoattractants and other soluble stimuli. Evidence that the same oxidase is activated by different transductional mechanisms. J Clin Invest 1983;72:192-200

30. Dahinden CA, Fehr J, Hugli TE. Role of cell surface contact in the kinetics of superoxide production by granulocytes. J Clin Invest 1983;72:113-21

31. Ernst JD, Decazes JM, Sande MA. Experimental pneumococcal meningitis: role of leukocytes in pathogenesis. Infect Immun 1983;41:275-9

32. Hammerschmidt DE, Weaver LJ, Hudson LD, Craddock PR, Jacob HS. Association of complement activation and elevated plasma-C5a with adult respiratory distress syndrome. Pathophysiological relevance and possible prognostic value. Lancet 1980;1:947-9 
33. Heflin AC Jr, Brigham KL. Prevention by granulocyte depletion of increased vascular permeability of sheep lung following endotoxemia. J Clin Invest 1981;68:1253-60

34. Ognibene FP, Martin SE, Parker MM, Schlesinger T, Roach P, Burch C, Shelhamer JH, Parrillo JE. Adult respiratory distress syndrome in patients with severe neutropenia. $\mathrm{N}$ Engl J Med 1986;315:547-51

35. Suter S, Schaad UB, Roux L, Nydegger UE, Waldvogel FA. Granulocyte neutral proteases and pseudomonas elastase as possible causes of airway damage in patients with cystic fibrosis. J Infect Dis 1984;149:523-31

36. McCord JM. Free radicals and inflammation: protection of synovial fluid by superoxide dismutase. Science 1974;185: 529-31

37. Greenwald RA, Moy WW. Ef fect of oxygen-derived free radicals on hyaluronic acid. Arthritis Rheum 1980;23:455-63

38. Chan PH, Fishman RA, Caronna J, Schmidley JW, Prioleau $\mathrm{G}$, Lee J. Induction of brain edema following intracerebral injection of arachidonic acid. Ann Neurol 1983;13:625-32

39. Chan PH, Fishman RA. The role of arachidonic acid in vasogenic brain edema. Fed Proc 1984;43:210-3

40. Chan PH, Kerlan R, Fishman RA. Reductions of $\gamma$ aminobutyric acid and glutamate uptake and $\left(\mathrm{Na}^{+}+\mathrm{K}^{+}\right)$ATPase active in brain slices and synaptosomes by arachidonic acid. J Neurochem 1983;40:309-16

41. Chan PH, Fishman RA. Transient formation of superoxide radicals in polyunsaturated fatty acid-induced brain swelling. J Neurochem 1980;35:1004-7

42. Lesse AJ, Quagliarello VJ, Moxon ER, Scheld WM. The role of leukocytes and type b capsule in experimental Haemophilus influenzae meningitis [abstract 747]. In: Program and abstracts of the 26th Interscience Conference on Antimicrobial Agents and Chemotherapy. Washington, DC: American Society for Microbiology, 1986

43. Täuber MG, Shibl AM, Hackbarth CJ, Larrick JW, Sande MA. Antibiotic therapy, endotoxin concentration in cerebrospinal fluid, and brain edema in experimental Escherichia coli meningitis in rabbits. J Infect Dis 1987;156: 456-62

44. Fishman RA. Brain edema. N Engl J Med 1975;293:706-11

45. Syrogiannopoulos GA, Olsen KD, Reisch JS, McCracken GH
Jr. Dexamethasone in the treatment of experimental Haemophilus influenzae type b meningitis. J Infect Dis 1987; 155:213-9

46. Conner WT, Minielly JA. Cerebral oedema in fatal meningococcaemia [letter]. Lancet 1980;2:967-9

47. Quagliarello VJ, Long WJ, Scheld WM. Morphologic alterations of the blood-brain barrier with experimental meningitis in the rat. Temporal sequence and role of encapsulation. J Clin Invest 1986;77:1085-95

48. Shenkin HA, Bouzarth WF. Clinical methods of reducing intracranial pressure. Role of the cerebral circulation. $\mathbf{N}$ Engl J Med 1970;282:1465-71

49. Sokoloff L. Relation between physiological function and energy metabolism in the central nervous system. J Neurochem 1977;29:13-26

50. Pappius HM. Dexamethasone and local cerebral glucose utilization in freeze-traumatized rat brain. Ann Neurol 1982;12: $157-62$

51. Baird DR, Whittle HC, Greenwood BM. Mortality from pneumococcal meningitis. Lancet 1976;2:1344-6

52. Giampaolo C, Scheld WM, Savory J, Sande MA, Wills MR, Boyd JC. A multivariate approach to prognostication in experimental bacterial meningitis. Am J Clin Pathol 1981; 76:442-9

53. Täuber MG, Tuomanen E, Zak O, Sande MA. Increased intracranial pressure induced by pneumococcal cell walls [abstract 683]. In: Program and abstracts of the 25th Interscience Conference on Antimicrobial Agents and Chemotherapy. Washington, DC: American Society for Microbiology, 1985

54. Tuomanen E, Tomasz A, Hengstler B, Zak O. The relative role of bacterial cell wall and capsule in the induction of inflammation in pneumococcal meningitis. $J$ Infect Dis 1985;151:535-40

55. Tuomanen E, Liu H, Hengstler B, Zak O, Tomasz A. The induction of meningeal inflammation by components of the pneumococcal cell wall. J Infect Dis 1985;151:859-68

56. Tuomanen E, Hengstler B, Rich R, Bray MA, Zak O, Tomasz A. Nonsteroidal anti-inflammatory agents in the therapy for experimental pneumococcal meningitis. J Infect Dis 1987;155:985-90 